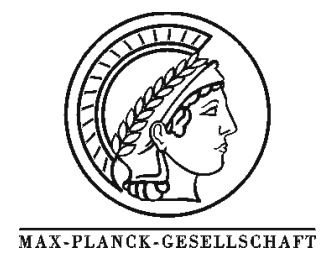

\title{
Interface-dependence of Nucleation and Self-Assembly of Ultrathin Iron Oxide Films
}

\author{
G. Ketteler, W. Ranke*
}

Department of Inorganic Chemistry, Fritz-Haber-Institute of the MPG, Faradayweg 4-6, 14195 Berlin, Germany

* Corresponding author: e-mail ranke@ffhi-berlin.mpg.de, phone +49 308413 4523, fax +49 3084134401

Submitted 01 April 2003

\begin{abstract}
The interface-dependence of heteroepitaxial growth of iron oxide films is investigated by scanning tunneling microscopy (STM) and low -energy electron diffraction (LEED). We show that the different chemical affinity to the metal substrate (Ru vs. Pt) and the step density (basal vs. vicinal $\mathrm{Pt}$ ) significantly influence nucleation, heteroep itaxial crystal growth, and adhesion. Repeated Fe deposition-oxidation cycles lead to a StranskiKrastanov growth mode on all substrates. On $\mathrm{Ru}(0001)$, metastable $\mathrm{FeO}(111)$ layers with strongly expanded lattice consta nts with a thickness up to 4 monolayers (ML) can be obtained by one-minute oxidation of the corresponding amount of Fe. Homogeneous nucleation of self-assembled, periodic $\mathrm{Fe}_{3} \mathrm{O}_{4}(111)$ nanodomains embedded in an ultrathin $\mathrm{FeO}(111)$ film occurs on $\mathrm{Ru}(0001)$ in $4 \mathrm{ML}$ thick FeO(111) films. Nucleation of $\mathrm{Fe}_{3} \mathrm{O}_{4}(111)$ islands below $4 \mathrm{ML}$ on $\mathrm{Ru}(0001)$ occurs preferentially at substrate step edges while on Pt(111), no influence of surface defects was observed. On a vicinal Pt substrate, the terrace width and step height triplicates under influence of the wetting FeO(111) film. Differences in the growth behavior are discussed in terms of the involved surface and interface free energies.
\end{abstract}

\section{Introduction}

Oxide compounds are used in a vast variety of applications, for example as magnetic devices, ionic superconductors, catalysts, surface coatings, etc. Iron oxides occur in different oxidation states and crystal structures with different properties and are utilized, e.g., in magnetic storage media or as heterogeneous catalysts for the dehydrogenation of ethylbenzene $[1,2]$.

The intrinsic characteristics of such compounds are strongly modified when the length scales determining these properties become of the order of the spatial extent of the system. Some properties of compounds are mainly due to surface effects such as the catalytic activity, or are altered due to the reduced atomic coordination at a surface such as the magnetic properties [3]. Ultrathin films may differ from the thermodynamically expected bulk phases and interfacestabilized phases may form [4-6]. Also the adhesion between two materials is strongly influenced by the chemical interaction at an atomic scale.

Differences in the adhesive behavior of two materials can be rationalized by considering the energies associated with the change of surface area to interface area when an interface between two materials is formed [7]. The energy balance $\Delta \gamma=\gamma_{\mathrm{f}}+\gamma_{\text {in }}-\gamma_{\mathrm{s}}$ determines the growth mode of a deposited material $\left(\gamma_{\mathrm{f}}, \gamma_{\mathrm{s}}\right.$ : surface free energy of the deposited film and a substrate, respectively; $\gamma_{\text {in }}$ : interface free energy). For $\Delta \gamma>0$, the formation of compact islands (Volmer-Weber growth mode) is anticipated while $\Delta \gamma<0$ leads to wetting layers with a high surface and interface area (Frank-Van der Merwe growth mode). Generally, the surface free energy of oxides is higher than of metals, therefore most metals tend to form compact particles on oxide substrates whereas oxide films are dispersed on metal substrates. However, the dispersion of different metals on the same oxide substrate may differ significantly $[8,9]$, and it has recently been demonstrated that Co films can be forced to wet an alumina substrate after hydroxilation [10]. These effects are determined by specific interactions at the interface such as the chemical affinity, strain due to a lattice mismatch, etc, and thus the interface free energy $\gamma_{\text {in }}$. For $\gamma_{\text {in }}$ $<0$, even dissolution and formation of an interface alloy is expected [14]. The interaction of interface layers (interfactants) $[11,12]$ or surfactants $[13]$ which lower the interface or surface free energy, respectively, may also lead to otherwise unexpected wetting films. On the other hand, a high lattice mismatch may generate oxide islands on a metal substrate although the surface free energies would favor a layer-by-layer growth $[15,16]$.

Surface irregularities such as steps or kinks lead to a higher contact area of the film with the substrate, and thus a low interface energy may lead to a preferential nucleation at these sites when the condition $\gamma_{\text {in }}<\gamma_{\mathrm{s}}+\gamma_{\mathrm{f}}$ is fulfilled [7]. Finally, also growth kinetics has to be considered, as high deposition rates or low temperatures lead to an insufficient mobility of surface atoms for equilibration, so that continu- 
ously multilayers may form from a supersaturated precursor (pseudo-Frank-Van der Merwe growth mode).

To summarize, modifications of the interface energetics by the growth conditions or by a modification of the interface region may have decisive influence on the preferential nucleation site, the growth morphology and adhesion between two compounds. This is discussed in this article for the growth of iron oxide films on different metal substrates.

\section{Experiment}

Iron oxides were grown on single-crystalline $\mathrm{Ru}(0001)$, $\operatorname{Pt}(111)$ and $\operatorname{Pt}(9$ 11 11$)$ substrates. The Pt crystals were cleaned by repeated cycles of Ar-sputtering and annealing to $1300 \mathrm{~K}$. Ru crystals were annealed at higher temperatures $(1450 \mathrm{~K})$. A vicinal Pt crystal was created by cutting a $\operatorname{Pt}(111)$ single crystal by $5.2^{\circ}$ along the [ $\left.\overline{2} 11\right]$ direction. Iron was evaporated from an iron wire wrapped around a resistively heated tungsten filament. Scanning tunneling microscopy (STM) and low-energy electron diffraction (LEED) measurements were performed in an ultrahigh vacuum chamber which is part of a multi-chamber system [17]. The chamber contains facilities for gas dosage, Ar- sputtering, a combined backview LEED and AES optics and a STM head (Burleigh). STM measurements were performed in the constant current mode with electrochemically etched tungsten tips.

\section{Results \\ 1. Growth of ultrathin iron oxide films}

On various substrates, iron oxides grow in form of ultrathin $\mathrm{FeO}(111)$ films with a thickness of a few monolayers (ML). $\mathrm{On} \mathrm{Ru}(0001)$ and $\mathrm{Pt}(111)$, quite different coincidence structures are formed as shown in fig. 1. Details of both structures can be found in previous publications [18,19]. $\mathrm{FeO}(111)$ films on $\mathrm{Ru}(0001)$ grow with a thickness of up to $4 \mathrm{ML}$ and are perfectly aligned with the atomic rows of the substrate and coincidence is achieved by locking either 6 or $7 \mathrm{FeO}$ units on $8 \mathrm{Ru}$ atom sites with a concomitant lattice constant expansion to 3.58 or $3.08 \AA$ (bulk FeO: $3.04 \AA$ ), respectively (fig. 1a) [18]. On $\operatorname{Pt}(111)$, a maximum $\mathrm{FeO}(111)$ thickness of $2.5 \mathrm{ML}$ can be obtained. The lattice constant of the $\mathrm{FeO}(111)$ films is less strongly expanded and a thickness-dependent coincidence is achieved by a slight rotation of the films (fig. 1d) [19].
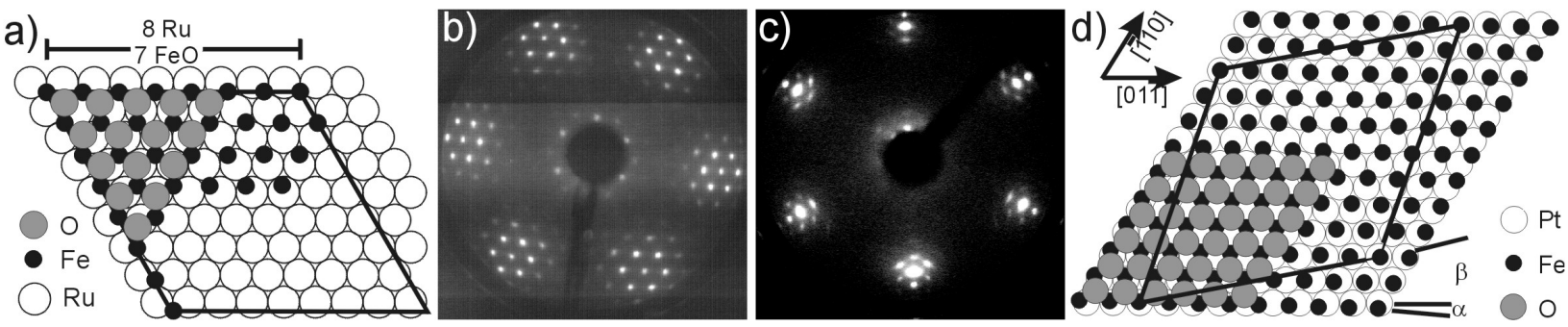

Figure 1: Coincidence structures and corresponding LEED patterns of $\mathrm{FeO}(111)$ monolayer films on $\mathrm{Ru}(0001)(\mathrm{a}, \mathrm{b})$ and $\mathrm{Pt}(111)(\mathrm{c}, \mathrm{d})$.

As similar growth conditions have been used on both substrates, the different coincidence structures should be caused by the different interaction at the interface. On both substrates the $\mathrm{FeO}(111)$ film is spatially clearly separated from the substrate, therefore $\gamma_{\text {in }}$ is positive in both cases. However, the interface energy $\gamma_{\text {in }}$ in the case of $\mathrm{FeO} / \mathrm{Ru}$ very likely is lower than for $\mathrm{FeO} / \mathrm{Pt}$ : Despite the slightly larger lattice mismatch $(14 \%$ on $\mathrm{Ru}(0001), 11 \%$ on $\mathrm{Pt}(111))$, simple, unrotated "6 on 8 " or "7 on 8 "coincidence structures are observed on $\mathrm{Ru}(0001)$, even if this requires a tremendous lattice constant expansion. On $\mathrm{Pt}(111)$, the $\mathrm{FeO}(111)$ film does not align with the atomic rows of the substrate but rather seems to "float" on the substrate indicating a weaker interaction. Further, these films are less stable than on $\operatorname{Ru}(0001)$ where thicker $\mathrm{FeO}(111)$ films can be obtained. Remarkably, also on a $\mathrm{Pt}(100)$ substrate $\mathrm{FeO}$ films grow with the polar (111) termination, even though the hexagonal reconstruction of the clean $\mathrm{Pt}(100)$ does not form under influence of a growing $\mathrm{FeO}$ film, and thus hexagonal $\mathrm{FeO}(111)$ films form on a substrate with square symmetry [20]. Shaikhutdinov et al. suggested therefore that the lattice mismatch between substrate and film is of minor importance for the growing iron oxide film. However, this might not be true for more strongly interacting substrates where the growing oxide film aligns with the substrate atoms.

\section{Nucleation and Growth of $\mathrm{Fe}_{3} \mathrm{O}_{4}$ (111) islands}

On Ru and Pt substrates, a Stranski-Krastanov-type growth mode of $\mathrm{Fe}_{3} \mathrm{O}_{4}(111)$ islands on a $\mathrm{FeO}(111)$ wetting layer occurs when the growth is thermodynamically controlled, i.e., by successive deposition and oxidation of iron [16]. High oxide deposition rates can be realized by depositing large amounts of iron and short oxidation times (however, long enough to ensure stoichiometric conversion to the corresponding iron oxide). On $\mathrm{Ru}(0001)$, this approach leads to a homogeneous nucleation of self-assembled, periodically arranged $\mathrm{Fe}_{3} \mathrm{O}_{4}$ nanodomains embedded in an $\mathrm{FeO}(111)$ Moiré structure when $\sim 4 \mathrm{ML} \mathrm{Fe}$ are deposited and oxidized (fig. 2) [18]. On Pt(111), no difference was reported using either repeated deposition-oxidation cycles [15] or one-minute-oxidation of $3 \mathrm{ML} \mathrm{Fe}$ deposited in one turn [21].

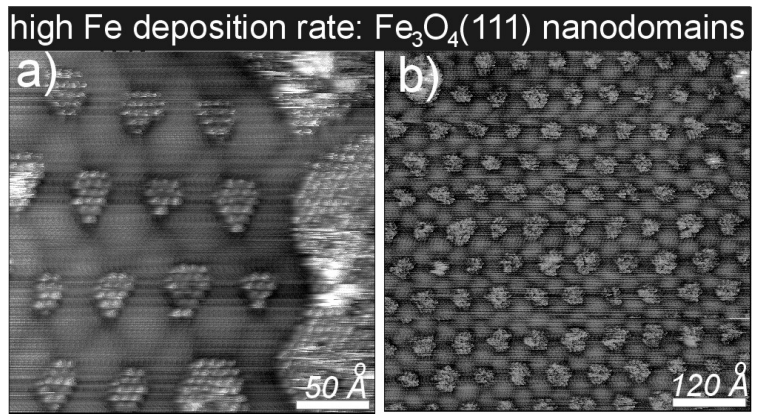

Figure 2: Periodically arranged $\mathrm{Fe}_{3} \mathrm{O}_{4}(111)$ nanodomains after one-turn deposition of $\sim 4 \mathrm{ML} \mathrm{Fe}$ and subsequent oxidation. (a) 250x250 $\AA^{2}$ STM image of atomically resolved $\mathrm{Fe}_{3} \mathrm{O}_{4}(111)$ domains embedded in a $\mathrm{FeO}(111)$ film. (b) $600 \times 600 \AA^{2}$ region of an extended terrace.

Again, these differences should be caused by the different chemical interaction at the interface with both metals. Generally, a layer-by-layer growth of $\mathrm{FeO}(111)$ on both substrates is expected from the high surface free energies of the metals and the low surface free energy of $\mathrm{FeO}$, respectively (Pt: $2.3 \mathrm{~J} / \mathrm{m}^{2}$; Ru: $2.9 \mathrm{~J} / \mathrm{m}^{2} ; \mathrm{FeO}: 0.6 \mathrm{~J} / \mathrm{m}^{2}$ [16]). However, the island growth mode of $\mathrm{Fe}_{3} \mathrm{O}_{4}\left(\gamma_{\mathrm{f}}=0.4 \mathrm{~J} / \mathrm{m}^{2}\right)$ 
can only be explained by a high interfacial energy due to the lattice mismatch with both substrates.

On $\mathrm{Ru}(0001)$, the homogenous nucleation of $\mathrm{Fe}_{3} \mathrm{O}_{4}$ nanodomains occurs when the critical thickness for $\mathrm{Fe}_{3} \mathrm{O}_{4}$ nucleation is exceeded [16]. For a stoichiometric conversion, this requires a thickness of at least $4 \mathrm{ML} \mathrm{FeO.} \mathrm{As}$ $\mathrm{FeO}(111)$ films are polar, thick films should not be stable $[22,23]$. However, as discussed in a previous publication, these films are stabilized electrostatically by a strong lattice constant expansion due to the strong interaction with the $\mathrm{Ru}$ substrate so that, unlike on Pt substrates, even thicker $\mathrm{FeO}(111)$ films can be stabilized [18]. Details on the growth on both substrates can be found in previous publications $[15,16,18]$.

\section{Influence of the substrate step morphology}

As discussed in the introduction, increased contact areas and diffusion characteristics on stepped or kinked surfaces may affect nucleation and growth. In heterogeneous catalysis, one has long become aware of a different chemical reactivity due to altered adsorption properties of defective or complex surfaces, often responsible for the so-called 'material gap' [24]. We have thus turned to investigations of the influence of substrate steps to growth and adhesion. On $\mathrm{Pt}(111)$, no influence of substrate defects on the $\mathrm{Fe}_{3} \mathrm{O}_{4}$ island formation was observed and a homogeneous nucleation was assumed [15]. This is different from growth on $\mathrm{Ru}(0001)$, where a preferential nucleation of $\mathrm{Fe}_{3} \mathrm{O}_{4}$ islands at step edges has been observed (fig. 3a) [16].

As outlined in the introduction, for $\gamma_{\text {in }}<\gamma_{\mathrm{s}}+\gamma_{\mathrm{f}}$ nucleation is expected to occur on terraces while for $\gamma_{\text {in }}>\gamma_{\mathrm{s}}+\gamma_{\mathrm{f}}$ nucleation should preferentially take place at steps or kinks [7]. Preferential nucleation at steps on $\mathrm{Ru}(0001)$ can thus be explained by the slightly higher surface free energy of $\mathrm{Ru}$ compared to $\mathrm{Pt}\left(2.93\right.$ vs. $\left.2.34 \mathrm{~J} / \mathrm{m}^{2}\right)[16]$ and is also inline with the proposed lower interface energy for the stronger interacting $\mathrm{FeO} / \mathrm{Ru}$ system.

Experiments on a vicinal $\mathrm{Pt}$ substrate, $\operatorname{Pt}(9$ 11 11$)$, revealed essentially a similar Stranski-Krastanov growth mode as on Pt(111) (fig. 3b). First, the growing $\mathrm{FeO}(111)$ film changes the step structure of the clean Pt substrate and more kinks are formed at the substrate step edges (fig. 4a). After deposition of $\sim 1 \mathrm{ML} \mathrm{FeO}(111)$, the substrate morphology has significantly changed and triple steps separating terraces with a triplicated width $(\sim 75 \AA)$ have formed (fig. 4). At this stage, $\mathrm{Fe}_{3} \mathrm{O}_{4}$ islands start to nucleate (fig. 3b).

It has been calculated that the surface free energies of vicinal oxide surfaces deviate considerably from the low-index surface planes $\left(\gamma_{\text {vicinal }}(\right.$ Oxide $)>\gamma_{\text {basal }}($ Oxide $\left.)\right)$ due to the more localized electronic structure of partially covalent compounds when compared to vicinal metal surfaces which have a similar surface free energy as the low-index surface planes $\left(\gamma_{\text {vicinal }}(\right.$ Metal $) \approx \gamma_{\text {basal }}($ Metal $\left.)\right)$ [25]. Additionally, for polar oxide surfaces, the formation of more stable facets (e.g., autocompensated $\mathrm{FeO}(100)$ ) may become important as, for instance, has been reported for $\alpha$ -

$\mathrm{Al}_{2} \mathrm{O}_{3}(1010)$ after annealing [26]. Even if the additional energy cost for the formation of triplicated steps (or nanofacets) has to be considered, these effects cause the observed tendency for the formation of extended low-index
FeO(111) surface planes separated by nanofacets. This is similar to the previously reported restructuring of vicinal Pt surfaces due to changes in the surface free energies in reactive atmosphere (e.g., upon chemisorption of oxygen) $[27,28]$. Terrace width extensions of stepped oxides have been reported for $\mathrm{MgO}(100)$ [29] and $\alpha-\mathrm{Al}_{2} \mathrm{O}_{3}(0001)$ [30]. In the latter case, the terrace width was very uniform $(\sim 100 \mathrm{~nm})$ and this was attributed to repulsive and attractive interactions between the steps; maybe similar interactions lead to the uniform triplicated terrace width of $\mathrm{FeO}(111)$ films on $\mathrm{Pt}(9 \mathrm{11} 11)$.
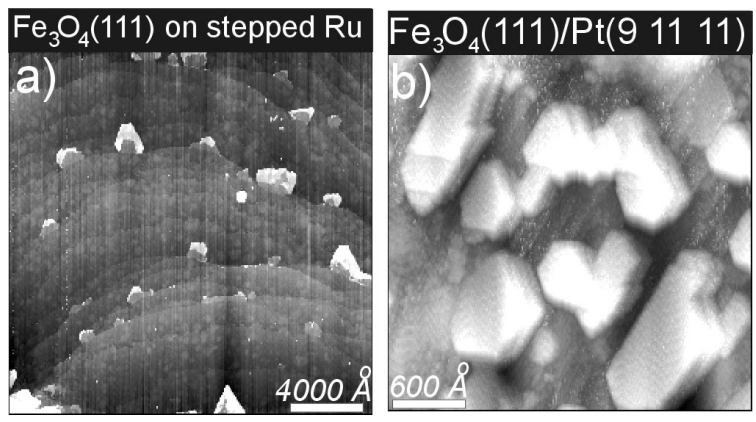

Figure 3: (a) $2 \times 2 \mu \mathrm{m}^{2} \mathrm{STM}$ image of $\mathrm{Fe}_{3} \mathrm{O}_{4}(111)$ islands nucleating at step edges from a closed $\sim 3 \mathrm{ML} \mathrm{FeO}(111)$ film after extended oxidation. (b) $3000 \times 3000 \AA^{2} \mathrm{STM}$ image of $\mathrm{Fe}_{3} \mathrm{O}_{4}(111)$ islands grown on a $\operatorname{Pt}\left(\begin{array}{llll}1 & 1 & 11\end{array}\right)$ substrate.
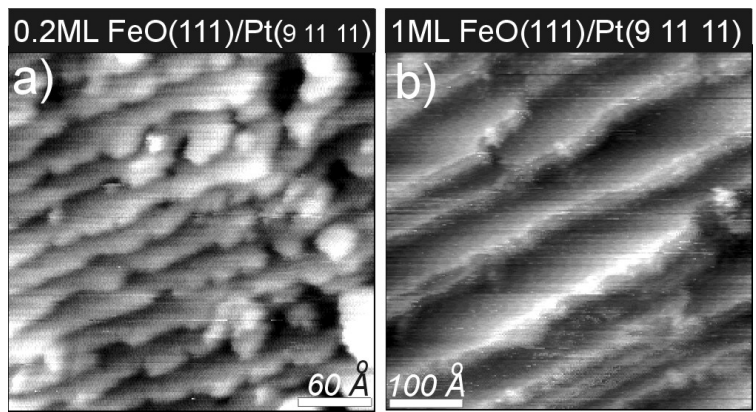

Figure 4: (a) $300 \times 300 \AA^{2}$ STM image of $\operatorname{Pt}(911$ 11) after formation of $\sim 0.2 \mathrm{ML} \mathrm{FeO}(111)$. Note the increased formation of kinks at the substrate step edges. (b) 500x500 $\AA^{2}$ STM image after deposition of $\sim 1 \mathrm{ML} \mathrm{FeO(111).} \mathrm{The} \mathrm{step} \mathrm{height} \mathrm{and} \mathrm{terrace} \mathrm{width}$ has triplicated.

\section{Conclusions}

We have investigated the interaction of thin iron oxide films with $\mathrm{Ru}$ and $\mathrm{Pt}$ substrates. We could show that the interface energy is of major importance for the structure of the growing film. The chemical (or electronic) nature in combination with the geometric structure (e.g. steps) significantly influence processes such as nucleation, crystal growth and adhesion between two materials leading to a quite different heteroepitaxy of iron oxides on $\mathrm{Ru}$ and $\mathrm{Pt}$ substrates.

\section{References}

[1] J. W. Geus, Appl. Catal. 25 (1986), 313.

[2] W. Weiss, R. Schlögl, Top. Catal. 13 (2000), 75.

[3] J. Shen J. Kirschner, Surf. Sci. 500 (2002), 300.

[4] S. Surnev, G. Kresse, M. G. Ramsey, F. P. Netzer, Phys. Rev. Lett. 87 (2001), 086102.

[5] F. P. Netzer, Surf. Rev. Lett. 9 (2002), 1553.

[6] G. Ketteler, W. Weiss, W. Ranke, R. Schlögl, Phys. Chem. Chem. Phys. 3 (2001), 1114. 
[7] E. Bauer, Z. Kristallogr. 110 (1958), 372; 395.

[8] M. Heemeier, S. Stempel, S. K. Shaikhutdinov, J. Libuda, M. Bäumer, R. J. Oldman, S. D. Jackson, H.-J. Freund, Surf. Sci. 523 (2003), 103. [9] U. Diebold, Surf. Sci. Rep. 48 (2003), 53.

[10] S. A. Chambers, T. Droubay, D. R. Jennison, T. R. Mattson, Science 297 (2002), 827.

[11] Th. Schmidt, E. Bauer, Phys. Rev. B62 (2000), 15815.

[12] G. Ketteler, W. Ranke, R. Schlögl, Adv. Mater., submitted 24.02.03.

[13] I. Markov, Mat. Chem. Phys. 49 (1997), 93.

[14] J. Tersoff, Phys. Rev. Lett. 74 (1995), 434.

[15] W. Weiss, M. Ritter, Phys. Rev. B59 (1999), 5201

[16] G. Ketteler, W. Ranke, J. Phys. Chem. B (2003), in press.

[17] W. Weiss, M. Ritter, D. Zscherpel, M. Swoboda, R. Schlögl, J. Vac. Sci. \& Technol. A16 (1998), 21.

[18] G. Ketteler, W. Ranke, Phys. Rev. B66 (2002), 033405.

[19] W. Ranke, M. Ritter, W. Weiss, Phys. Rev. B60 (1999), 1527

[20] Sh. K. Shaikhutdinov, M. Ritter, W. Weiss, Phys. Rev. B62 (2000), 7535.

[21] Y. J. Kim, C. Westphal, R. X. Ynznza, Z. Wang, H. C. Galloway, M. Salmeron, M. A. Van Hove, C. S. Fadley, Surf. Sci. 416 (1998), 68.

[22] P. W. Tasker, J. Phys. C: Solid State Phys. 12 (1979), 4977.

[23] C. Noguera, J. Phys.: Cond. Matter 12 (2000), R367.

[24] J. H. Larsen, I. Chorkendorff, Surf. Sci. Rep. 35 (1999), 165.

[25] P. W. Tasker, D. M. Duffy, Surf. Sci. 137 (1984), 91.

[26] J. R. Heffelfinger, C. B. Carter, Surf. Sci. 389 (1997), 188.

[27] D. W. Blakely, G. A. Somorjai, Surf. Sci. 65 (1977), 419.

[28] E. Hahn, H. Schief, V. Marsico, A. Fricke, K. Kern, Phys. Rev. Lett. 72 (1994), 3378.

[29] S. S. Kim, S. Baik, H. W. Kim, C. Y. Kim, Surf. Sci. Lett. 294 (1993), L935.

[30] O. Kurnosikov, L. Pham Van, J. Cousty, Surf. Int. Anal. 29 (2000), 608. 